\title{
Para além de Tordesilhas: itinerários incertos
}

Beyond Tordesilhas: Uncertain Itineraries

Márcia Regina Capelari Naxara *,

\section{Resumo}

A floresta amazônica, literária e imaginariamente construída como região que ultrapassa as fronteiras brasileiras, é central às reflexões deste artigo. As referências iniciais aos textos paradigmáticos de Joseph Conrad (Coração das Trevas) e Alberto Rangel (Inferno Verde), em narrativas que constroem espaços, viagens e caminhos percorridos, buscam traduzir o fascínio pelo desconhecido - trevas, inferno - assim nomeados com relação ao mundo considerado civilizado na virada para o século $\mathrm{XX}$. Ponto de partida para leituras relacionadas às narrativas e discursos sobre a Amazônia, que oscilaram entre o elogio e a detratação: "terra bruta", espaços que ultrapassam a linha de Tordesilhas, apontando para diferentes Brasis em suas especificidades e para a constante presença e permanência do lado obscuro da modernidade. Finalizo por referenciar leituras contemporâneas que abordam a região em sua universalidade pelo alargamento de horizontes e concepções, bem como pela aproximação de diferenças.

Palavras-chave: Amazônia; natureza; literatura; viagens; imaginário.

\section{Abstract}

The Amazon rainforest, which has been imaginarily and literarily constructed as a region that extends beyond the Brazilian borders, is crucial to the reflections of this article. The opening references to the paradigmatic books written by Joseph Conrad (Heart of Darkness) and Alberto Rangel (Green Hell), grounded in narratives that construct spaces, journeys and paths, try to express the fascination with the unknown (darkness, hell), which is to say, to terms that are nominated in relation to the civilized world at the turn to the 20th century. This is a starting point for interpretations dealing with narratives and discourses on the Amazon rainforest that oscillate between eulogy and detraction: "raw land" and spaces beyond the line of the Treaty of Tordesilhas that point to different Brazils, according to their specificities and the constant presence and permanence of the dark side of modernity. I finish the article with references to contemporary interpretations that grasp the region in its universality as an effort at broadening the horizons and conceptions as well as at approximating differences.

Keywords: the Amazon rainforest; nature; literature; journeys; imaginary.

\footnotetext{
* Universidade Estadual Paulista "Júlio de Mesquita Filho" (Unesp), Faculdade de Ciências Humanas e Sociais (FCHS), Franca, SP, Brasil. mrnaxara@uol.com.br <https://orcid.org/0000-0002-5793-1696>
} 


\section{I.}

Inicio por duas citações significativas que, individualizadas e/ou como excertos dos textos de que fazem parte, constituem visões, percepções e relatos de lugares e naturezas bastante diversas que, no entanto, podem ser aproximadas: a bacia do rio Congo na costa Atlântica da África e a do rio Amazonas na América do Sul, e suas respectivas florestas. Paisagens vistas e avaliadas como primordiais em sua magnitude, abrigando forças de naturezas capazes de aproximar e propiciar vivências e experiências que transitam entre os sentimentos do belo e do sublime com que se procura traduzir, em palavras e imagens, $o$ contato e os embates entre homem e natureza, bem como dos homens em sua diversidade. No caso específico, os personagens e espaços que, tanto Conrad como Rangel constroem, na primeira década do século XX, constituem formas com que intentam adentrar mundos - exteriores e interiores -, perscrutando ambivalências de vida e sentimentos nas relações do homem com a natureza, com vistas a nos deter na que nos fala mais de perto, a Amazônia.

Joseph Conrad $^{2}$ encerra Coração das Trevas (1902) em narrativa que leva o leitor a acompanhar o gesto do personagem narrador - Marlow - cujo olhar perscrutava o horizonte do ponto de vista do perene desaguar do Tâmisa no Atlântico; horizonte em que vislumbrava o "mar sem fim" (português, no verso de Fernando Pessoa), em seus possíveis (des)caminhos e experiências vinculadas à presença da cobiça e da escuridão entre os homens: "A vista do mar alto estava bloqueada por um banco de nuvens negras, e o curso de água sereno que leva aos rincões mais distantes a Terra corria escuro sob um céu encoberto - parecia conduzir ao coração de uma treva imensa" (Conrad, 2008, p. 121). ${ }^{3}$

Alberto Rangel ${ }^{4}$ abre o conto "Inferno Verde" (1908) com uma pequena e significativa epígrafe de Victor Hugo - "Seu coração, sobre o qual pesa um espanto sombrio, ergue-se preso a torturas convulsivas. Parece ter vislumbrado o inferno em vida, e que lhe tenha sido revelado algo maior que o desespero". ${ }^{5}$ Último texto entre as "Scenas e Scenarios do Amazonas", que fecha o volume de mesmo título - Inferno Verde (Rangel, 1927). O conjunto forma um mosaico de visões e quadros da natureza que traduzem extremos marcados pelas significações de "inferno" e "paraíso", em que o autor trabalha com as intensas e, por vezes, abruptas alterações do mundo natural - inconstâncias e variações, por vezes imperceptíveis, por vezes extremas, traduzidas em forte e específica linguagem. Nele, como em alguns dos demais contos do volume, Rangel procura transportar o leitor ao ambiente sombrio e escuro da floresta para, entre os obscuros sussurros e ruídos, a que se mesclam estertores de agonia, 
acompanhar o incidente que, repentinamente, deixou o personagem - Souto - desterrado no sertão da floresta e das águas amazônicas. Já embarcado para o retorno à "civilização", ocorre a repentina mudança: "Uma nódoa acinzentada, que de repente se apagou aos silvos, obumbrando-se no punhado luxuriante das canaranas, sororocas e embaúbas, era o 'gaiola' que deixava o Souto no alto Juruá, desterrado para a lucta, na delirante vida de explorar um sertão. O chaveco voltava precipitadamente. Tinha sido o ultimo a subir, em arrojo imprudente..." (Rangel, 1927, p. 243).

Dois pequenos excertos - de Conrad e Rangel - expressivos, ambos, no dizer de lugares do mundo, então por explorar. Mundo que se perde, no primeiro caso, num horizonte longínquo do Atlântico para alcançar e, só então, afunilar na escuridão do rio Congo e chegar aos locais mais longínquos de exploração do marfim; horizonte que, por sua vez, falta ao segundo, pois o Amazonas corre - caudaloso -, em meio à mata fechada, carregando obstáculos, sem horizonte a descortinar na atmosfera sufocante da floresta que contém a extensa e dispersa exploração do caucho, lugar em que o personagem se vê perdido e sem esperança.

No primeiro, as palavras finais de Coração das Trevas exprimem o contraste - não propriamente dual - entre civilização e barbárie, em encontro profundo dos desejos obsessivos do europeu cultivado com a escuridão e a violência que envolvem o comércio do marfim na costa da África; o misterioso Kurtz procurado, também de forma obsessiva, por Marlow, o personagem narrador - autorreferenciado em Conrad - que conta a história em enredo que, gradativamente, vai desvelando ao leitor o ambiente do rio e de suas margens, entremostrando sombras que abrigam e escondem os habitantes locais. Marlow era personagem já conhecido dos leitores pelo conto Juventude, de 1898, em que Conrad narra suas primeiras experiências nos mares, então profundamente marcadas pelo desejo de conhecimento do Oriente (Conrad, 2003).

No segundo, o narrador, na pena de Rangel, busca a aproximação da saga vivida pelo personagem Souto, engenheiro atraído para a Amazônia na expectativa de enriquecimento pela exploração do látex e que, no último momento, se vê preso em sua tentativa primeira de sair e retornar ao lar para, na sequência, tentar tão somente sobreviver ao "inferno verde": às intempéries, às cheias, à malária - e, enfim, à loucura. O parágrafo final do conto encerra o seu destino: "Adiantando-se a tarde, o caboclo Miguel começou a algumas braças da tapera, vagarosamente, a cavar uma sepultura” (Rangel, 1927, p. 243).

Enredos, de um e outro - Conrad e Rangel -, beirando sentidos com relação às formas de expressão literária do maravilhoso e do monstruoso 
vinculados à natureza, em leitura que, de forma ampla, investe em experiências narrativas que vinculam e amarram vivências e imaginários que aproximam e tocam a grandiosidade e beleza, assim como o "perverso" e a "perversão" nela contidos; e, sem dúvida também nos homens, em termos de estranhamentos e alteridades; quebram e simultaneamente mantêm visões e imagens idílicas, bem como sonhos nebulosos, buscando a compreensão de mundos e de relações entre homens e naturezas em seus diferentes e diversos ambientes. Ambos contêm sentidos de atrações irresistíveis - aventura, cobiça, ambição, curiosidade, conhecimento, domínio, força - a movimentar homens e máquinas, colocando em contato temporalidades e culturas diversas.

Narrativas que guardam relação com as formas de exercício do domínio e das disputas coloniais, no caso do Congo, e com os movimentos realizados no Brasil visando a sua unidade e integração territorial, que contiveram elementos próximos e, também, diferenciados nos espaços em que se manifestaram. Avanços considerados civilizacionais em ambos os locais, carregando em seus conteúdos tanto os princípios de nacionalidade, identitários, como o domínio político e exploração econômica. Espaços, ambos, complexos em suas especificidades. Somando aos interesses dos Estados nacionais e, em paralelo, o movimento dos autores que acompanha a curiosidade pelo diferente e pelo desconhecido nos mistérios que podem conter o contato com o "outro" - seja o além-mar, nas terras de domínio colonial; seja a Amazônia, como parte das "terras interiores" do continente americano, em grande parte brasileiras. A trajetória percorrida por Marlow partiu do estuário do Tâmisa percorrendo o Atlântico e adentrando o continente africano pelo rio Congo, em direção ao denominado pelo autor Coração das Trevas, à época propriedade privada do rei Leopoldo II da Bélgica, tendo a exploração do marfim e da borracha como atividades centrais, realizadas com o confisco de terras e aldeias congolesas, com trabalho escravo e submissão violenta das populações locais. A Amazônia, Inferno Verde nesta escolha específica de Rangel, constituía espaço ainda pouco explorado, compartilhado por várias nações que haviam conquistado sua independência na primeira metade do século XIX, tendo alimentado ao longo do tempo imaginário bastante complexo, como abordado mais adiante. Despertou de forma continuada a curiosidade e o interesse, tanto pela ambição de ampliação do conhecimento, como pela exploração de suas riquezas naturais que, desde os primeiros registros da viagem de Francisco de Orellana (1511-1546) e Frei Gaspar de Carvajal (1504-1584), estiveram no horizonte e na imaginação. 


\section{II.}

Inferno Verde, de Alberto Rangel - texto não muito fácil e por vezes hermético - foi "traduzido" ao leitor por Euclides da Cunha, em prefácio que contém rasgados elogios. Nas palavras de Euclides, Rangel expressara, praticamente decalcando, a "natureza nova", de algo que é "phantástico e incompreensível" - a Amazônia -, na intenção de "impressionabilidade artística que tentou abranger o conjunto da terra e surpreender-lhe a vida maravilhosa". Afirma que Inferno Verde,

a começar pelo título, devia ser o que é: surpreendente, original, extravagante; feito para despertar a estranheza, o desquerer; [...].

Porque é um livro bárbaro. Bárbaro, conforme o velho sentido clássico: extranho. Por isto mesmo, todo construído de verdades, figura-se um acervo de phantasias. (Cunha, 1927, p. 6-7)

Leituras sobre a Amazônia que se apoiam no viajar e conhecer e, também, na literatura pregressa sobre ela produzida. No caso específico, escritor e prefaciador comungavam dos mesmos princípios do cientificismo positivista, trabalhando com a associação entre arte e ciência como forma de dizer do mundo e de dar a ler a Amazônia (sobre o tema ver Nascimento, 2011; Leandro, 2011a; 2011b; 2012). Em aproximação a tais princípios podemos reconhecer, também, tanto em Rangel como em Euclides, a permanência de um romantismo de base, ou, melhor dizendo, de uma sensibilidade romântica que, concordando com Jacó Guinsburg, adentrou e atravessou o século XX brasileiro (Guinsburg, 1985, p. 13-21), parecendo chegar até nós, em pleno século XXI. Sensibilidade que colaborou para que a sua complexa natureza - do Brasil -, não somente, mas em especial com relação às terras interiores, fosse vista $\mathrm{e}$ avaliada de forma contraditória e ambivalente, entre o seu enaltecimento e, mesmo, o impacto de sua grandiosidade e beleza - por sua dimensão e complexidade - que "teve como contrapartida a desqualificação de grande parte da sua população, efetivada tanto por viajantes e observadores estrangeiros como por brasileiros" (Naxara, 2001; 2004).

Construção e narração dos espaços interiores do Brasil como um outro ou outros Brasis, que acentuam a percepção e os sentimentos de alteridade; que continuam a enaltecer a sua natureza, guardando, com persistência, um imaginário que a concebe entre extremos. Sensibilidades que, quando aguçadas, esbarram no sublime, suplantando a imaginação para, por vezes, alcançar 
o medo e o horror, com a permanente contrapartida do belo. Aproximam o leitor a sensações inauditas e nem sempre racionalmente explicáveis - tanto em termos de paralisação como de exaltação dos sentidos, difíceis de serem traduzidos em palavras. A experiência de Euclides da Cunha é paradigmática quando do relato de seu primeiro contato visual com o Amazonas: a decepção com o anteriormente sonhado e imaginado ao desembarcar e visualizar o rio. Nada da magnitude antecipada marca o primeiro desapontamento, seguido da euforia encantada que, curiosamente, mais que da observação da natureza ao primeiro entardecer, veio da leitura tresnoitada de texto do naturalista Bates (cedido por Goeldi), que o fez descortinar e vislumbrar, na manhã seguinte, o que qualificou como "um daqueles 'glorious days' de que nos fala Bates", ao ver o Amazonas acalentado em seus sonhos, em paisagem que expressava, com suas águas, a grandiosidade e o trabalho da natureza em eterna reconstrução (Cunha, 1975, p. 157-158; Naxara, 2017).

Ana Pizarro, em "Imaginário y Discurso: la Amazonia” (Pizarro, 2005), considerando a magnitude latino-americana da floresta busca afirmar a existência de uma unidade da região em meio às diferenças culturais e políticas que a conformam, tendo em vista os oito Estados soberanos abarcados pelo amplo território, assim como as variações próprias e internas a cada um deles: Brasil - sua maior parcela -, Venezuela, Colômbia, Equador, Peru, Bolívia, Suriname, Guiana (e Guiana Francesa), com elementos identitários próprios que, no entanto, confluem para o dimensionamento da unidade Amazônia como região que recebe olhares diferenciados sob pontos de vista também diferenciados; olhares que alimentaram e alimentam disputas regionalizadas, internacionalizadas e, hoje, globalizadas e tornadas crescentemente agudas.

Unidade que, por variadas formas, é regulada pelo tempo das águas em suas incertas margens, em intrincado traçado que vai cortando e recortando a floresta, entre rios e afluentes que formam a imensa bacia do Solimões/ Amazonas, por entre matas de várzea, igapós e inúmeros varadouros. Extenso bioma que, do lado brasileiro, confina com o cerrado, na direção do Pantanal, compondo o mapa do que podemos chamar espaços interiores do Brasil. Pizarro centra sua abordagem na Amazônia como "construção discursiva" que ganhou variações ao longo do tempo - espaço físico e cultural, em que atuaram dispositivos simbólicos e imaginários com efetividade ao longo de sua existência. Construções que tiveram entre seus elementos o ver-se - o europeu - no espelho do outro - o selvagem. Na perspectiva interna ao Brasil pode-se também acrescentar a essencial importância geopolítica, que adquiriu consistência e historicidade crescente nos significados atribuídos à interiorização para além 
de Tordesilhas em termos do traçado e da conformação identitária que veio a configurar o seu mapa político.

O primeiro momento teria sido constituído pelo espaço/tempo que medeia entre os séculos XV e finais do XVII, marcado pela presença primeira dos "descobridores", seguidos da ocupação missionária e das viagens científicas que elaboraram as primeiras construções e imagens da Amazônia como "espaço paradisíaco e infernal”, tanto no sentido inicialmente atribuído pelas missões religiosas, como no que se abriu à fantasia das "terras incógnitas" apontada, nos lembra Pizarro, por Sérgio Buarque de Holanda, em Visão do Paraíso (1992). Paraíso terrestre que teria tido continuidade no tempo, mesmo que acompanhado de espectros negadores dessa "fantasia" que, ainda que por vezes colocada em dúvida, seguiu sempre atuante (Holanda, 1992; Naxara, 2004), com desdobramentos e polêmicas que oscilaram entre apreensões extremas de otimismo e detratação, que podem ser acompanhados no alentado estudo, O Novo Mundo, de Antonello Gerbi (Gerbi, 1996). Processo que, nas reflexões de Hannah Arendt, vinha ocorrendo desde a tenra modernidade, marcada por profundas alterações na relação dos homens com sua existência no mundo (Arendt, 1993, cap. VI; Naxara, 2004, p. 41-62).

Discursos em que foi se acentuando o "caráter mais racional" a partir do século XVIII, com base nos princípios iluministas de sistematização do conhecimento, com os quais se buscou descrever, classificar e compor o "quadro da natureza", na perspectiva do Sistema de Lineu (1735), além dos esforços para a visualidade da conformação da Terra, de que resultou a viagem de La Condamine, segunda "grande entrada", seguida pelas viagens científicas de Wallace, Spruce e Humboldt, que não pôde entrar no Brasil (Pizarro, 2005, p. 141; Naxara, 2004, p. 48-62). Escritos que continuam a conter elementos fantasiosos, mas que se encontram já no escopo do pensamento racional e científico essencial para a ambição de domínio das forças e aproveitamento da natureza pelo homem.

E, terceiro ponto, o discurso do século XIX, que avança pelo século XX, vinculado à exploração do caucho, momento em que "os imaginários naufragam e os prejuízos da modernidade tornam-se porosos, tensionam e, por vezes, explodem" (Pizarro, 2005, p. 142). Convivem o fausto e sofisticação do Teatro Amazonas - em sua "deslumbrante magnificência" - com a gritante contraposição de pobrezas extremas, além dos também extremos significados a unir, em longa cadeia, a extração da borracha e sua utilização nos novos utensílios modernos (calçados e pneumáticos, entre outros), icônicos da modernidade tornada possível e que podemos ler em À margem da história, de Euclides da 
Cunha (1909) e em El processo del Putamayo e sus secretos inauditos, de Carlos Vacárcel (1915) (Pizarro, 2005, p. 145). Assim como seu avesso simbólico, bem próximo ao "Inferno Verde" de Rangel e que não concorre propriamente com o Teatro - já que este guarda permanência no tempo -, aproximando-se, isto sim, das ruínas da modernidade, ou melhor, da "modernidade na selva" que, entre outros empreendimentos, constituiu a construção da ferrovia MadeiraMamoré entre 1907 e 1912 (Hardman, 2005).

Período, este último, de que fazem parte as narrativas aqui consideradas, que continuam a ser histórias do maravilhoso e dos extremos da modernidade - entre inferno e paraíso; maravilha e ruína - e das sensações não somente produzidas, mas também alimentadas a partir das leituras dos escritos anteriores e das novas vivências crescentemente experimentadas. Imagens paradisíacas e, simultaneamente, infernais, pelas possibilidades que abrem a construções imaginárias opostas: do "bom selvagem" em suas virtudes naturais, não corrompidas pela civilização; e da natureza acolhedora, em construções que estabelecem e acentuam os contrapontos com a civilização e, simultaneamente, buscam acentuar suas possibilidades em termos civilizacionais e de domínio da natureza pelo homem.

\section{III.}

Colocações com que se pode retomar o fio central dos itinerários incertos que marcaram e continuam a marcar a exploração das enormes áreas interiores do Brasil, para além de Tordesilhas. Considerando os séculos XIX e XX direcionados para o futuro, verificamos a convivência de construções e visões da natureza que transitam incessantemente entre o elogio e a detratação; entre extremos que caminham do mal absoluto para a idealização e o bem, também em sentidos absolutos. Cabe notar que a população amazônica que aparece e povoa os contos que formam o volume e, em especial o denominado "Inferno Verde" de Rangel, é cabocla, composta por adventícios, misturados às populações mestiças locais, exploradores do caucho no caso específico, deixando praticamente na invisibilidade a população indígena. A tensão homem/natureza aparece de forma forte, mas não é encontrada, na mesma medida, para as relações homem/homem, em especial as populações caboclas e indígenas.

A natureza aparece em destaque quase absoluto. Euclides da Cunha já anuncia na introdução a Inferno Verde a (im)possibilidade quanto ao conhecimento da Amazônia, num esforço definido como "guerra de mil anos contra o desconhecido". Difícil vislumbrá-la: 
O triumpho virá ao fim de trabalhos incalculáveis, em futuro remotissimo, ao arrancarem-se os derradeiros véus da paragem maravilhosa, onde hoje se nos esvaem os olhos deslumbrados.

Mas então não haverá segredos na própria Natureza. A definição dos últimos aspectos da Amazonia será o fecho de toda a História Natural. (Cunha, 1927, p. 4-5).

Aproximação realizada no "claro-escuro do desconhecido" (Cunha, 1927, p. 9), de que vale a pena lembrar sua referência a dois dos contos do volume - "Maibi" e "Hospitalidade" -, pela transcrição de longo trecho em que compara o "homem decaído", o caboclo que tinha suas terras e vida tomadas por algum "potentado", quando de sua teima em permanecer, "para ficar na sua terra e para sempre, enterra-se vivo e morre”. A comparação é operada na naturalização do homem e em seu símile com a natureza - da "Hiloe encantadora" de Humboldt, aos tentáculos de homens e parasitas consumindo vidas. Nas palavras de Euclides imagem e aproximação ganham força:

Maibi, é a imagem da Amazonia mutilada pelas myriades de golpes das machadinhas homicidas dos seringueiros. Na Hospitalidade, o homem decahido, volve, em segundos, por um milagre de atavismo, à tona da humanidade, antes de mergulhar de uma vez na sombra, dia a dia mais espessa, da sua decrepitude moral irremediável.

$[\ldots]$

O homem mata o homem como o parasyta aniquila a arvore. A Hiloe encantadora, de Humboldt, dá-lhe esta lição medonha:

$\mathrm{O}$ apuiseiro é um polvo vegetal. Enrola-se ao indivíduo sacrificado, extendendo sobre ele milhares de tentáculos. [...] E é a lucta sem um murmúrio. Começa pela adaptação ao galho atacado de fio lenhoso, vindo não se sabe d’onde. Depois, esse filete entumesce, e, avolumado, se põe, por sua vez, a proliferar em outros. Por fim, a trama engrossa e avança, constrangente, para malhetar a presa, a que se substitue completamente. Como um sudário, o apuiseiro envolve um cadáver; o cadáver apodrece, o sudário reverdesce inmortal. (Cunha, 1927, p. 15-16, grifo meu)

Os contos, portanto, constroem narrativas em que se acentua a sombria e poderosa grandiosidade da floresta, de onde emerge o "inferno" - imagem central que, no conto específico, marca a saga vivida pelo personagem Souto que, como sabemos, não retorna, sendo literalmente consumido pelas forças da natureza, manifestadas nas águas do Amazonas e na floresta. A narrativa 
foi fechando perspectivas pela construção de imagens sombrias que preparam o trágico e solitário final. O texto de Rangel é forte ao adentrar o espaço sufocante que envolve Souto em seus momentos finais: "Foi assim, entre o silencio respeitoso do Miguel e a palrice dos outros homens, que o Souto chegou a uma barraquinha deserta, abafada entre velhas pacoveiras. O bananal apertava a barraca; a floresta suffocava o bananal; e, por sua vez, o céo esmagava a floresta. Foi esse o primeiro pouso do Souto, no remoto confluente do Solimões" (Rangel, 1927, p. 250, grifo meu).

As imagens da natureza construídas ao longo do caminho percorrido pelo personagem possibilitam visualizar o incessante movimento da floresta, como que orquestrado por uma incansável e sempre vitoriosa natureza, mais uma vez personificada em sentimentos, movimentos e cores: "A floresta soffria, a floresta ria... Dedos convulsos de um gênio em delírio tangiam as cordas infinitas d'essa grande harpa de esmeralda, arrancando-lhe acordes e syncopes harmoniosos ou incoerentes, na execução confusa da mais aterrorizante das symphonias" (Rangel, 1927, p. 252).

Da doença de Souto, que acabou por lhe ser fatal, o autor relata as derradeiras esperanças: "Tinha ainda fé, confiava... Aquillo havia de passar. O quinino triumpharia... mas o Souto se descarnava. Cada vinte horas de accessos, cada reduzir de energias e de músculos. Oito dias assim” (Rangel, 1927, p. 266).

E a imagem infernal assoma da última agonia de Souto que morre, "apostrofando á matta, esposada com o rio", em seus últimos momentos:

- Inferno!... Inferno... verde!

$[\ldots]$

Não houve éco que apanhasse e devolvesse as palavras de fel dos lábios do Vencido. A terra ambiente com ellas ganhava o dístico e o ferrete: - INFERNO VERDE ! (Rangel, 1927, p. 279-280)

Rangel, ao finalizar, elabora uma possível resposta da terra ao homem ocidental, sem dúvida. Espécie de vaticínio em que, aí sim, ganha relevo a figura do indígena e da sua vivência e relação com a natureza. A imagem do inferno como resposta da investida e ambição do homem moderno - explorador, civilizadamente bárbaro, já com outro sentido daquele utilizado por Euclides no início, ou seja, como não civilizado, tomado em sentido amplo.

Perdoo-te e compreendo o estigma que me lanças. Fui um paraíso. Para a raça íncola nenhuma pátria melhor, mais farta e benfazeja. Por mim as tribos erra- 
vam, no sublime desabafo dos instintos de conservação, livres nas marnotas pelas bacias fluviais afora. [...] Inferno é o Amazonas... inferno verde do explorador moderno, vândalo inquieto, com a imagem amada das terras d'onde proveio carinhosamente resguardada na alma ansiada da paixão por dominar a terra virgem que barbaramente violenta. [...] Tanta lagrima e tanto sofrimento são o apanágio do passageiro tempo, que antecede as vitorias... Não se me vence a sorrir... Exijo os sacrifícios que os antigos deuses reclamavam: sangue e morte. [...] Que um Poeta solenize, no esplendor de estrofes perfeitas, as Vítimas e a Derrota; o fecho do poema aludirá ao meu Destino, à glória do VALLE FECUNDISSIMO - reino das Aguas correntes, horto das Orquídeas e Palmeiras, império das Heveas e Uaupé assús!... (Rangel, 1927, p. 280-282)

\section{IV.}

Escritos que conferem centralidade à contraposição entre natureza e civilização, bem como às diferentes leituras que guardam permanência no tempo. A escolha do título, "Para além de Tordesilhas" veio de uma série de reportagens recentes, publicadas em O Estado de S. Paulo - "Terra Bruta" -, que resultaram de incursão realizada por dois repórteres e dois fotógrafos que percorreram regiões centrais - "coração do Brasil" - registrando situações que acentuam o contraste entre as construções imaginárias da natureza e a violência - pregressa e atual - da sua ocupação e exploração. Caminhos dos antigos bandeirantes; caminhos das atuais rodovias federais:

Os focos da violência se concentram na parte do território que, no período colonial, ficava a oeste do Tratado de Tordesilhas. Hoje, a travessia da faixa imaginária continua a expor a prática de ultrapassar o limite da civilização, diante do olhar interessado do Estado e de grupos econômicos. (Borges et al., 2016)

"Inferno Verde" e "Terra Bruta" - expressões a que podemos atribuir diversos sentidos - explicitam a existência de diferentes Brasis em suas especificidades. Lugares difundidos como paraísos, em delimitações mais ou menos imprecisas para a circulação de visitantes, com relação às áreas em que, como registra a reportagem, imperam a violência e a destruição. Limites, ou sua ausência, em excessos presentes nas grandes investidas do agronegócio, de que resulta o crescente desmatamento, não somente, mas em especial na Amazônia. ${ }^{6}$ Imensa área geográfica essa das terras interiores, que ganha força exemplar na pequena e incisiva citação tomada a Lévi-Strauss (Tristes Trópicos, 1955) por 
Foot Hardman como epígrafe introdutória a Trem Fantasma: a ferrovia Madeira-Mamoré e a modernidade na selva (Hardman, 2005), acentuando contrastes que nos são tão característicos e que guardam permanência no tempo: "Quem vive ao longo da linha Rondon facilmente se julgaria na Lua. Imagine-se um território do tamanho da França, três quartos inexplorado; percorrido somente por pequenos bandos de indígenas nômades que estão entre os mais primitivos que se possam encontrar no mundo; e atravessado de ponta a ponta por uma linha telegráfica" (Lévi-Strauss apud Hardman, 2005, p. 8).

Hardman, além de outras reflexões vinculadas à temática, chama a atenção para a associação história e ruína presente na literatura dos dois autores aqui aproximados - Euclides da Cunha e Alberto Rangel - que, por sua vez, busquei aproximar a Joseph Conrad em termos da tragicidade do vivido em meio às ruínas marcadas por interesses de diferentes ordens, que levaram homens/personagens a querer conhecer o que seriam os "confins" do mundo - o contato com a natureza virgem, com os seus exploradores e com povos então considerados selvagens (para além, sem dúvida, das riquezas possíveis) - de modo que a tragicidade desponta dos dois lados com que se procura traçar a linha do civilizado ou incivilizado (não ou pouco civilizado), em especial quando a população - indígena - é subsumida ao mundo natural, como dele fazendo parte.

Construções que - para o caso do Brasil - viriam de "primeiros" ou "antigos" modernistas, na perspectiva da história como eterno choque de temporalidades, com acento para a tragicidade da vida humana - "história como coleção de ruinarias" (Hardman, 1996, p. 294); ou seja, em verdadeiro embate entre natureza e civilização, inferno e paraíso, que deixou atrás de si a devastação: devastação da natureza, em suas forças desmedidas, e devastação dos homens, também desmedida em processos nem sempre civilizacionais; "imaginário moderno das ruínas" que, na afirmação de Huyssen, "permanece consciente do lado obscuro da modernidade” (Huyssen, 2014, p. 99).

Imensa região que, além de extrapolar o nacional em sua territorialidade, como já assinalado, teve sua relevância desde sempre reconhecida e contemporaneamente amplificada, ao se considerar o quadro geopolítico mundial. Algumas reflexões recentes, sem dúvida entre outras, somam, recompõem e ampliam os itinerários - alguns mais incertos que outros - dos caminhos e conhecimento da Amazônia.

No prefácio assinado por Willi Bolle, Edna Castro e Marcel Vejmelka ao livro Amazônia: região universal e teatro do mundo (Bolle; Castro; Vejmelka, 2010, p. 7-16) os organizadores reúnem estudos em torno da região 
conferindo-lhe posição de destaque em termos da sua importância e projeção como universal e central ao mundo dos homens tomados em termos planetários. Reconhecendo e trabalhando a historicidade das mais remotas aproximações vinculadas ao início, exploração e "descobrimento" da região, Bolle buscou vivenciar, pela leitura e pela recomposição de trajetos outrora percorridos, a experiência da floresta - espírito com que refez, em 2007, o percurso de Francisco de Orellana (1541-1542), reiterando metafórica, real e literariamente, a atenção para a centralidade da região na sua totalidade (Bolle, 2010, p. 19-56):

Os conceitos de "região universal" e "teatro do mundo", aqui aplicados à Amazônia, foram tomados de empréstimo a Goethe (a ideia de "literatura universal") e a Calderón (a metáfora do Grande Teatro do Mundo), para tentar compreender melhor essa região e sua importância para o nosso planeta, em termos de geopolítica como de imaginário internacional. (Bolle; Castro; Vejmelka, 2010, p. 7-8)

O conjunto das reflexões, retomando marcos da história e da literatura sobre a região, aponta para os riscos frente à ocupação econômica desenfreada e sem projeção global de prejuízos ambientais a não muito longo prazo. Decorrem dos contatos entre povos no complexo e contínuo movimento da modernidade de que resultou a ampliação do conhecimento do mundo, simultânea à aproximação de espaços, naturezas, gentes, culturas. Trilha dos "descobrimentos" que, ao longo do tempo, consolidou a perspectiva global com perdas identitárias parciais ou totais em que diferentes culturas e diferentes concepções de mundo foram, em grande parte, subsumidos à racionalidade e ciência ocidentais.

Alargando horizontes e aproximando diferenças em termos globais e universalizantes, Joachim Bernauer, no texto que fecha o volume, "O Amazonas como ópera: onde artemídia e teatro musical contemporâneo se encontram como os rios Negro e Solimões", aborda a montagem do teatro musical que então se encontrava em preparação (Bernauer, 2010) - espetáculo multimídia que veio a ser gravado na confluência dos rios Negro e Solimões, em projeto que envolveu o Instituto Goethe de São Paulo, de que Bernauer era diretor de cultura, com proposta de José Wagner Garcia e participação de Laymert Garcia dos Santos, no intento de colocar em cena, na confluência dos dois rios, a Ópera "Amazônia", associando a sonoridade da floresta e seus habitantes às mídias e arte contemporâneas (Senra, 2010). ${ }^{7}$

A universalidade e possibilidade de convivência de culturas e concepções de mundo presentes nesta e em outras iniciativas aproximam formas de 
entendimento do mundo que são simultaneamente próximas e distantes, não somente nas relações entre os homens, como entre os homens e a natureza, no mundo em que estamos imersos; amplas em seu dimensionamento e em sua diversidade; portadoras de alteridades que se movimentam em fronteiras fluidas e mutantes. Alteridades que marcam permanências mais ou menos conflituosas do mundo em suas diferenças nas formas predominantes com que tem sido interpretado e dado a conhecer pela cultura ocidental de matriz europeia, de que fazem parte os escritos de Joseph Conrad e Alberto Rangel, que nos falam de modo tão forte à sensibilidade.

Sensibilidade aguçada pela leitura de A queda do céu, de Davi Kopenawa e Albert Bruce (Kopenawa; Bruce, 2015), que tomaram parte ativa da montagem da Ópera “Amazônia”, cujo texto busca traduzir uma concepção outra do mundo como "teoria global do lugar". Ao afirmar uma só origem para todos os homens confere-se importância ao local e ao mundial, pela possível exclusão do nacional e das barreiras que lhe são inerentes, bem como dos olhares que acentuam diferenças. A perspectiva xamânica, baseada numa compreensão outra - ancestral - do mundo pela cultura Yanomami, afirma uma origem comum e compartilhada, não evolucionista e não restrita aos diferentes grupos humanos, mas a todos os seres vivos - homens, plantas e animais - propondo considerar igualmente os habitantes do planeta e a conformação de sua natureza.

Não são poucos os caminhos sinalizados, em especial se pensamos a configuração do que denominamos Brasil e, para além das nossas fronteiras, o significado contemporâneo da Amazônia. Cito, ao finalizar, dois pequenos excertos que incidem sobre a variedade do mundo e a que nos é específica, que ultrapassa Tordesilhas, na direção da longa tradição de oposição das terras interiores e litorâneas no pensamento sobre o Brasil, bem como o discurso civilizacional que fechou o século XIX e abriu o século XX, elaborado por autores que foram simultaneamente aderentes e críticos das formas de pensar os povos e os lugares em suas diferenças:

A conquista da Terra, o que na maior parte significa tirá-la daqueles que têm uma fisionomia diferente ou narizes ligeiramente mais achatados do que os nossos, não é uma coisa bonita quando você olha demais para ela. (Conrad, 2008, p. 15) ${ }^{8}$

Inferno é o Amazonas... inferno verde do explorador moderno, vândalo inquieto, com a imagem amada das terras d'onde veio carinhosamente resguardada na alma ansiada de paixão por dominar a terra virgem que barbaramente violenta. (Rangel, 1927, p. 281) 


\section{REFERÊNCIAS}

ARENDT, Hannah. A condição humana. (1958). Tradução: Roberto Raposo; posfácio Celso Lafer. 6. ed. Rio de Janeiro: Forense Universitária, 1993.

BERNAUER, Joachim. O Amazonas como ópera: onde artemídia e teatro musical contemporâneo se encontram como os Rios Negro e Solimões. In: BOLLE, Willi; CASTRO, Edna; VEJMELKA, Marcel (org.). Amazônia: região universal e teatro do mundo. São Paulo: Globo, 2010. p. 279-301.

BOLLE, Willi. A travessia pioneira da Amazônia (Francisco de Orellana, 1541-1542). In: BOLLE, Willi; CASTRO, Edna; VEJMELKA, Marcel (org.). Amazônia: região universal e teatro do mundo. São Paulo: Globo, 2010. p. 19-56.

BOLLE, Willi; CASTRO, Edna; VEJMELKA, Marcel. Apresentação. In: BOLLE, Willi; CASTRO, Edna; VEJMELKA, Marcel (org.). Amazônia: região universal e teatro do mundo. São Paulo: Globo, 2010. p. 7-16.

BORGES, André; NOSSA, Leonencio (textos); SAMPAIO, Dida; ROMERO, Hélvio (fotos). Terra Bruta: pistolagem, devastação e morte no coração do Brasil. O Estado de S. Paulo, Reportagem Especial, 10 a 17 jul. 2016, p. A10 (10 jul.). Disponível em: http://infograficos.estadao.com.br/politica/terra-bruta/. Acesso em: 17. jul. 2016.

BRUM, Eliane. A Amazônia não é nossa. Opinião. El País Brasil. Disponível em: https://brasil.elpais.com/brasil/2017/10/02/opinion/1506961759_879609.html. Acesso em: 15 out. 2017.

BRUM, Eliane. O chuchu quer conquistar a soja. Opinião. El País Brasil. Disponível em: https://brasil.elpais.com/brasil/2018/08/20/opinion/1534778209_605609.html. Acesso em: 20 ago. 2018.

CONRAD, Joseph. Coração das Trevas. (1902). Tradução: Sergio Flaksman. São Paulo: Companhia das Letras, 2008.

CONRAD, Joseph. Hearth of Darkness. (1902). Free EBooks at Planet Ebook.com. S. d. Disponível em: https://www.planetebook.com/heart-of-darkness/. Acesso em: 20 ago. 2018.

CONRAD, Joseph. Juventude: uma narrativa [e] O parceiro secreto. (1898/1902). Tradução: Valéria Medeiros. Rio de Janeiro: Paz e Terra, 2003.

CUNHA, Euclides da. Academia Brasileira de Letras (discurso de recepção). (1906). In: CUNHA, Euclides da. Contrastes e confrontos. São Paulo: Cultrix; Rio de Janeiro: INL-MEC, 1975. p. 157-175.

CUNHA, Euclides da. Preambulo. In: RANGEL, Alberto. Inferno Verde (Scenas e Scenarios do Amazonas). (1908). 4. ed. Rio de Janeiro: Typographia Arrault \& Cia., 1927. p. 1-22.

GERBI, Antonello. O Novo Mundo: história de uma polêmica. (1750-1900). (1996). Tradução: Bernardo Joffily. São Paulo: Companhia das Letras, 1996. 
GUINSBURG, Jacó. Romantismo, historicismo e história. In: GUINSBURG, Jacó (org.). O Romantismo. (1978). São Paulo: Perspectiva, 1985. p. 13-21.

HARDMAN, Francisco Foot. Brutalidade antiga: sobre história e ruína em Euclides. Estudos Avançados, São Paulo: USP, v. 10, n. 26, p. 293-310, 1996.

HARDMAN, Francisco Foot. Trem fantasma: a ferrovia Madeira-Mamoré e a modernidade na selva. (1988). 2. ed. revista e ampliada. São Paulo: Companhia das Letras, 2005.

HOLANDA, Sérgio Buarque de. Visão do paraíso: os motivos edênicos no descobrimento e colonização do Brasil. (1959-1968). 5. ed. São Paulo: Brasiliense, 1992.

HUYSSEN, Andreas. A nostalgia das ruínas. In: HUYSSEN, Andreas. Culturas do passado-presente: modernismos, artes visuais, políticas da memória. Tradução: Vera Ribeiro. Rio de Janeiro: Contraponto: Museu de Arte do Rio, 2014. p. 91-114.

IHGB. Perfil Sócios falecidos brasileiros. S. d. Disponível em: https://ihgb.org.br/perfil/ userprofile/arangel.html. Acesso em: 26 jun. 2019.

KOPENAWA, Davi; ALBERT, Bruce. A queda do céu: palavras de um xamã yanomami. (2010). Prefácio de Eduardo Viveiros de Castro. Trad. Beatriz Perrone-Moisés. São Paulo: Companhia das Letras, 2015.

LEANDRO, Rafael Voigt. Alberto Rangel e seu projeto literário para a Amazônia. 2011. Dissertação (Mestrado em Letras) - Programa de Pós-Graduação em Literatura, Instituto de Letras, Universidade de Brasília (UnB). Brasília: 2011 a.

LEANDRO, Rafael Voigt. O projeto literário amazônico de Alberto Rangel. In: COLÓQUIO INTERNACIONAL POÉTICAS DO IMAGINÁRIO. Amazônia: Literatura e Cultura, 3., 2012, Manaus, Brasil. Anais..., 2012. p. 351-357.

LEANDRO, Rafael Voigt. Representação Literária da Amazônia na obra de Alberto Rangel. Revista Intercâmbio dos Congressos de Humanidades, Brasília: Congresso Internacional de Humanidades, UnB, 14., 2011b. Disponível em: http://unb.revistaintercambio.net.br/24h/pessoa/temp/anexo/1/275/231.pdf. Acesso em: 2 maio 2018.

NASCIMENTO, José Leonardo do. Euclides da Cunha e a estética do cientificismo. São Paulo: Ed. Unesp, 2011.

NAXARA, Márcia Regina Capelari. Cientificismo e sensibilidade romântica: em busca de um sentido explicativo para o Brasil no século XIX. Brasília: Ed. UnB, 2004.

NAXARA, Márcia Regina Capelari. Fronteiras do oeste brasileiro: caminhos arquitetados, imagens idealizadas. In: CONGRESO AHILA, 18. En los márgenes de la Historia Tradicional: Nuevas miradas de América Latina desde el siglo XXI, València: Universitat de València, España, set. 2017. (mimeo.).

NAXARA, Márcia Regina Capelari. Natureza e civilização: sensibilidades românticas em representações do Brasil no século XIX. In: BRESCIANI, Stella; NAXARA, 
Márcia Regina Capelari. Memória e (res)sentimento: indagações sobre uma questão sensível. Campinas: Ed. Unicamp, 2001. p. 431-455.

PAES, José Paulo. Posfácio: Conrad ou a crise do herói. In: CONRAD, Joseph. Nostromo. (1904). Tradução e posfácio: José Paulo Paes. São Paulo: Companhia das Letras, 2007. p. 499-528.

PIZARRO, Ana. Imaginario y discurso: la Amazonia. In: JOBIM, José Luís et al.

Sentidos dos lugares. Rio de Janeiro: Abralic, 2005. p. 130-151.

RANGEL, Alberto. XI. Inferno Verde. In: RANGEL, Alberto. Inferno Verde (Scenas e Scenarios do Amazonas). (1908). Prefácio de Euclides da Cunha. 4. ed. Rio de Janeiro: Typographia Arrault \& Cia., 1927.

SENRA, Stella. Povo Yanomami põe a Amazônia na ópera. 2010. Disponível em: https://www.stellasenra.com.br/povo-yanomami-poe-a-amazonia-na-opera/. Acesso em: 18 jul. 2018.

\section{NOTAS}

${ }^{1}$ A autora é Pesquisadora CNPq-2.

${ }^{2}$ No Posfácio a Nostromo, de Joseph Conrad (Jósef Teodor Konrad Korzeniowski, Polônia, 1857 - Inglaterra, 1924), José Paulo Paes (1926-1998) indica a difícil delimitação de seus escritos, que transitariam sob a "rubrica de ficção de aventuras", com a presença de elementos como o "exótico" por comparação à Europa, a figura do herói e a aventura marcada pelo inesperado e pela experiência do desconhecido. Acrescenta, no entanto, a presença de "espessura psicológica" em seus personagens, cuja complexidade e verossimilhança alcançam alto poder de convencimento. Cabe lembrar a experiência de vida de Conrad, que se fez navegante, marinheiro a "serviço do império colonial da rainha Vitória" por 17 anos e, também, do imperialismo belga, o que lhe permitiu conhecer o Oriente e a África, mais especificamente o Congo. Além dos citados Coração das Trevas (1902) e Juventude: uma narrativa (1898) estão entre suas obras mais importantes: Lord Jim (1900), Nostromo (1904), O agente secreto (1907), Sob os olhos ocidentais (1911) e A linha de sombra (1917) (PAES, 2007). Há duas traduções usuais, entre as várias edições, para o título Heart of Darkness: Coração das Trevas e O Coração das Trevas. Optei pela utilização da primeira forma, na tradução editada, em 2008, pela Companhia das Letras.

3 "The offing was barred by a black bank of clouds, and the tranquil waterway leading to the uttermost ends of the earth flowed sombre under an overcast sky - seemed to lead into the heart of an immense darkness" (CONRAD, s. d., p. 130). Releitura de Heart of Darkness, em enredo que aborda a Guerra do Vietnã, foi realizada em 1979 com direção de Francis Ford Coppola e roteiro de John Milius em Apocalypse Now.

${ }^{4}$ Alberto do Rego Rangel (Recife, PE, 1871 - Nova Friburgo, RJ, 1945) foi aluno da Escola Militar da Praia Vermelha (Rio de Janeiro), onde conheceu Euclides da Cunha. Combateu na Revolta da Armada (1893). Demitiu-se do Exército em 1900 e, após passagem pelo 
Maranhão como engenheiro-militar, seguiu para Belém (PA) e, na sequência, para Manaus (AM) como engenheiro-civil, tendo sido Diretor-geral de Terras e Colonização, além de redator-chefe do jornal Comércio do Amazonas. Ingressou no Instituto Histórico e Geográfico Brasileiro (IHGB) em 1912 e, em 1923, na carreira consular. De seus escritos voltados para a região amazônica, destaco, além de Inferno Verde (Scenas e Scenários do Amazonas), de 1908, Sombras nágua: vida e paisagens no Brasil equatorial, de 1913, nunca reeditado, ambos contendo elementos do desconhecimento, mistério e fantasia que cerca a região. Aguas revessas, texto autobiográfico, segundo Rafael Leandro, biografa mais a "história de vida do Brasil" que a vida de Rangel (IHGB, s. d.; LEANDRO, 2011a, p. 161).

5 "Son coeur, sur qui pèse une stupeur morne, se soulève en proie à des tortures convulsives. Il semble qu'il vienne d’entrevoir l’enfer dans sa vie, et qu'il se soit révélé à lui quelque chose de plus que le désespoir." Han d'Islande, romance de juventude de Victor Hugo (1802-1885), de 1823 (tradução minha) (RANGEL, 1927, p. 243).

${ }^{6} \mathrm{~A}$ temática é constante no noticiário sobre a região. Destaco dois textos recentes que, ao colocar questões atuais, retomam formas históricas recentes de ocupação da região (BRUM, 2017; 2018).

${ }^{7}$ A Ópera "Amazônia - teatro música em três partes" foi apresentada em Munique, São Paulo e Roterdã, com incentivo do Instituto Goethe de São Paulo, da Bienal de Munique, do Centro de Arte e Tecnologia de Mídias (ZKM) e do Serviço Social do Comércio (Sesc), além da participação da Hutukara Associação Yanomami (HAY), aldeia de Watoriki, Boa Vista. Ver: http://www.goethe.de/ins/pt/lis/prj/ama/ptindex.htm.

8 "The conquest of the earth, which mostly means the taking it away from those who have a different complexion or slightly flatter noses than ourselves, is not a pretty thing when you look into it too much" (CONRAD, s. d., p. 8).

Artigo recebido em 13 de dezembro de 2018.

Aprovado em 20 de agosto de 2019. 